\title{
CARACTERIZAÇÃO DOS PIRÊNIOS E MÉTODOS PARA ACELERAR A GERMINAÇÃO DE SEMENTES DE MURUCI DO CLONE AÇU ${ }^{1}$
}

\author{
JOSÉ EDMAR URANO DE CARVALHO², WALNICE MARIA OLIVEIRA DO NASCIMENTO³
}

RESUMO - Pirênios (caroços) de murucizeiro (Byrsonima crassifolia (L.) Rich.) do clone Açu, um acesso da Coleção de Germoplasma de Fruteiras Tropicais da Embrapa Amazônia Oriental, foram caracterizados, e avaliados diferentes métodos para superação da dormência das sementes. Na caracterização dos pirênios, foram considerados os seguintes aspectos: cor, forma, peso, comprimento, diâmetro, número de sementes por pirênio e espessura das paredes internas e externas do endocarpo. Os tratamentos para superação da dormência foram: a) testemunha - pirênios não-submetidos a tratamento pré-germinativo; b) imersão em água durante 24 horas; c) imersão em solução de ácido giberélico $\left(500 \mathrm{mg} . \mathrm{L}^{-1}\right)$ durante 24 horas; d) imersão em água durante 24 horas seguida de fratura no endocarpo por compressão; e) imersão em solução de ácido giberélico (500 mg. $\left.\mathrm{L}^{-1}\right)$ durante 24 horas seguida de fratura no endocarpo por compressão. Observou-se que os pirênios do clone Açu são ovalados, com superfície reticulada, peso de 0,62 $\pm 0,09$ e comprimento e diâmetro de $1,10 \pm 0,07$ e 1,02 $\pm 0,09 \mathrm{~cm}$, respectivamente. Os pirênios geralmente contêm duas sementes (mínimo zero e máximo três), localizadas em lóculos cujas paredes externas são mais espessas que as internas. O endocarpo é permeável à água, e as sementes absorvem prontamente essa substância. As sementes representam $10,12 \% \pm 2,87 \%$ do peso do pirênio. Os melhores tratamentos para sobrepujar a dormência consistiram da imersão dos pirênios em solução de ácido giberélico ou em água, seguida de fratura no endocarpo. Os resultados obtidos indicam que a germinação das sementes de muruci do clone Açu é regulada por dois mecanismos de dormência: o primeiro representado pelo espesso e córneo endocarpo, o qual é permeável à água, mas oferece resistência mecânica ao crescimento do embrião, e o segundo, devido à dormência fisiológica.

Termos para indexação: Byrsonima crassifolia, dormência, giberelina.

\section{PYRENE CHARACTERIZATION AND METHODS TO ACELERATE GERMINATION OF MURUCI SEEDS OF THE CLONE AÇU}

ABSTRACT - Pyrenes (pits) of muruci (Byrsonima crassifolia (L.) Rich.), clone Açu, an accession of the Tropical Fruit Tree Germplasm Collection of Embrapa Eastern Amazonian were characterized and different methods to overcome the seed dormancy were evaluated. Pyrene color, shape, weight, length, diameter, number of seeds per pyrenes, and thickness of the external and internal walls of the endocarp were characterized; seed color, weight, length, diameter and thickness were characterized. The treatments to overcome seed dormancy were: : a) control; b) soaking in water for 24 hours; c) soaking in gibberellicc acid (500 mg.L-1) for 24 hours; d) soaking in water for 24 hours followed by compression fracturing of the endocarp; e) soaking in gibberellic acid (500 mg.L-1) for 24 hours and fracturing of the endocarp. The pyrenes of muruci "Açu" are ovate, with a reticulate surface design, creamy brown in color, weight $0.62 \pm 0.09 \mathrm{~g}$ and are $1.10 \pm 0.07 \mathrm{~cm}$ long by $1.02 \pm 0.09 \mathrm{~cm}$ in diameter. The pyrenes generally contain two seeds (minimum zero and maximum three), located in the loculus whose external walls are thicker than the internal walls. The endocarp is water permeable and the seeds absorb water rapidly. The seeds represent $10.12 \pm 2.87 \%$ of the pyrene weight. The best treatments to overcome dormancy were soaking in giberellic acid or water followed by fracturing the endocarp. This combination of results suggests that germination of muruci "Açu" seeds is regulated by exogenous and endogenous dormancy mechanisms. The first is caused by the endocarp, which offers considerable resistance to the growth of the embryo, and the second is the seed physiological dormancy.

Index terms: Byrsonima crassifolia, dormancy, gibberellin.

\section{INTRODUÇÃO}

O murucizeiro (Byrsonima crassifolia (L.) Rich.) é uma espécie frutífera da família Malpighiacea, com provável centro de origem e de dispersão na Amazônia (Cavalcante, 1996). Apresenta ampla distribuição geográfica no território brasileiro, ocorrendo espontaneamente, com maior freqüência e abundância, nas regiões Norte, Nordeste e Centro-Oeste. É também encontrado na região Sudeste, em particular nos Estados de Minas Gerais e São Paulo, porém de forma mais rara. Rompendo as fronteiras brasileiras, está disperso em todos os países que se limitam com a Amazônia Brasileira, e na América Central e no Caribe (Roosmalen, 1985; Morton, 1987; Cavalcante, 1996; Souza et al., 2006).

O muruci é um fruto carnoso, do tipo drupóide, com formato globoso ou oblongo, oriundo de ovário tricarpelado, contendo cada carpelo um óvulo (Barroso et al., 1999). O tamanho e o peso do fruto apresentam pronunciadas variações, sendo encontrados frutos com diâmetro entre 0,7 e $2,2 \mathrm{~cm}$, e peso entre 1,0 e 6,0 g. Essas características têm forte componente genético 
e independem do número de frutos que se desenvolvem nos rácemos (Carvalho et al., 2007).

A unidade de dispersão (diásporo) e de propagação do murucizeiro é o pirênio, popularmente denominado de caroço, que é constituído pelo conjunto endocarpo e sementes. Os pirênios apresentam formato arredondado ou ovalado, são rígidos e com superfície externa reticulada e contêm de uma a três sementes, sendo que com maior freqüência são encontradas três sementes, localizadas em lóculos individualizados e são diminutas em relação ao tamanho do caroço (Cavalcante, 1996; Carvalho et al., 2007). Quando os pirênios apresentam duas ou três sementes, somente uma é viável (Cavalcante, 1996).

As sementes não são utilizadas como unidades de propagação em decorrência da dificuldade de removê-las do interior do endocarpo sem que haja comprometimento do poder germinativo devido às danificações mecânicas decorrentes da operação de extração. Estão envolvidas por tegumento delgado, de cor creme e apresentam embrião espiralado, o qual representa a quase totalidade do volume da semente (Barroso et al., 1999). A radícula está situada na extremidade apical do pirênio e é facilmente danificada quando se efetua a remoção do endocarpo (Carvalho et al., 2007).

A porcentagem de germinação de sementes de muruci é normalmente baixa, lenta e com acentuada desuniformidade. Essas características são decorrentes do fato de que estão envolvidas pelo espesso endocarpo, o qual oferece resistência ao crescimento do embrião, não obstante existir a hipótese de dormência fisiológica (Carvalho et al., 1998; Carvalho et al., 2007; Sautu et al., 2006; Sautu et al., 2007). Dentro de um lote de pirênios de muruci, sempre existe pequena proporção cujas sementes germinam prontamente, pois não apresentam dormência fisiológica, e o endocarpo não oferece restrições à germinação (Calzavara, 1970; Carvalho et al., 1998; Carvalho et al., 2007).

Este trabalho foi efetuado com o objetivo de caracterizar os pirênios e estabelecer procedimentos para a superação da dormência de sementes de muruci do clone Açu.

\section{MATERIAL E MÉTODOS}

Foram utilizados pirênios oriundos de três plantas do clone Açu, um dos acessos da Coleção de Germoplasma de Fruteiras Tropicais da Embrapa Amazônia Oriental, estabelecida na sede dessa instituição em Belém-PA, o qual tem se destacado por sua produtividade, número de frutos por cacho e, principalmente, pelo peso dos frutos que, em média, é de 5,0 g, bastante superior ao da maioria dos tipos ocorrentes em populações naturais e em pomares da espécie.

Utilizaram-se pirênios provenientes de frutos que sofreram abscisão natural em novembro de 2006, os quais foram coletados no dia em que se desprenderam naturalmente da planta-mãe. Após a coleta, foram mantidos durante dois dias nas condições de ambiente natural de Belém (temperatura média de $26,8^{\circ} \mathrm{C}$ e umidade relativa do ar de $86,0 \%$ ) para que completassem a maturação, ocasião em que a porção polposa (mesocarpo) se apresenta com consistência mole. Quando os frutos atingiram esse ponto, efetuou-se, manualmente, a remoção da polpa e a lavagem dos pirênios em água corrente até que se apresentassem completamente livres de resíduos de polpa. Posteriormente, procedeu-se o enxugamento superficial com papel-toalha e a secagem em dessecador contendo sílica-gel, até que atingissem teor de água em torno de 5,0\%, quando, então, foram armazenados em sacos de papel em ambiente com temperatura em torno de $22,0^{\circ} \mathrm{C}$ e umidade relativa do ar de $37,0 \pm 3,0 \%$ até janeiro de 2007 , ocasião em que se iniciou a fase de experimentação.

A caracterização dos pirênios e das sementes foi efetuada com base em uma amostra de 100 unidades. Os pirênios foram caracterizados quanto à forma, coloração, peso, comprimento, diâmetro, peso e número de sementes por pirênio, relação percentual entre o peso das sementes e do pirênio, espessura das paredes externa e interna do endocarpo, freqüência de pirênios com zero, uma duas e três sementes, permeabilidade do endocarpo à água e peso, cor, comprimento, largura e espessura das sementes.

A freqüência do número de sementes nos pirênios foi determinada com base em quatro amostras de 100 pirênios.

A permeabilidade do endocarpo à água foi verificada semeando-se os pirênios entre papel mata-borrão, previamente umedecido com água e retirando amostras após $6 ; 12 ; 18 ; 24 ; 30$; $36 ; 42 ; 48 ; 54 ; 60 ; 66 ; 72 ; 96 ; 120$ e 144 horas. No momento da semeadura, os endocarpos apresentavam-se com teor de água de $5,2 \%$, e as sementes com 4,7\%. Para essa avaliação, foram utilizadas quatro repetições de dez pirênios, os quais, após os diferentes períodos de semeadura, foram divididos nas porções endocarpo e sementes, efetuando-se, então, a determinação do teor de água dessas duas estruturas. O teor de água foi determinado pelo método de estufa a $105 \pm 3^{\circ} \mathrm{C}$, durante 24 horas (Brasil, 1992).

Os seguintes tratamentos pré-germinativos foram testados com o objetivo de acelerar e aumentar a porcentagem de germinação: a) pirênios não-submetidos a tratamento prégerminativos (testemunha); b) imersão dos pirênios em água, durante 24 horas; c) imersão dos pirênios em solução de ácido giberélico na concentração de $500 \mathrm{mg} . \mathrm{L}^{-1}$, durante 24 horas; d) imersão dos pirênios em água, durante 24 horas, seguido de fratura no endocarpo por compressão; e) imersão dos pirênios em solução de ácido giberélico na concentração de 500 mg.L $\mathrm{L}^{-1}$, durante 24 horas, seguido de fratura no endocarpo por compressão.

A fratura no endocarpo foi obtida comprimindo-se individualmente os pirênios, no sentido da base para o ápice, em uma morsa de bancada. Por ocasião dessa operação, não se efetuou o descarte de pirênios com fraturas pronunciadas, mesmo quando se suspeitava que as sementes tivessem sofrido danificações mecânicas que pudessem comprometer a germinação. Tal procedimento foi adotado para se verificar a eficácia do método.

Após a aplicação dos tratamentos pré-germinativos, os pirênios foram semeados em caixas de plástico, contendo como substrato a mistura de areia e serragem, na proporção volumétrica de 1:1. Esse substrato foi previamente esterilizado em água fervente, durante duas horas. O experimento foi conduzido em delineamento inteiramente casualizado, com quatro repetições, 
nas condições de ambiente natural de Belém-PA (temperatura média de $26,8^{\circ} \mathrm{C}$ ). Cada parcela foi representada por 50 pirênios.

As seguintes características foram avaliadas: porcentagem de germinação, número de dias requeridos para o início da germinação, número de plântulas normais obtidas a partir de 50 pirênios e tempo médio de germinação.

A porcentagem final de germinação, assim como o número total de plântulas normais, obtidas a partir de 50 pirênios, foram computados 60 dias após a semeadura, considerando-se como germinada somente as sementes que deram origem a plântulas normais, ou seja, com todas suas estruturas essenciais perfeitamente desenvolvidas. No caso de pirênios que continham duas ou três sementes e todas deram origem a plântulas normais, somente a primeira que germinou, foi contada para fins de determinação da porcentagem de germinação, conforme recomendação de Brasil (1992).

$\mathrm{O}$ número de sementes germinadas em cada parcela foi anotado diariamente, para fins de elaboração das curvas de germinação e para estimativa do tempo médio de germinação (TMG), que foi calculado de acordo com a equação proposta por Edwards (1934) e conhecida como índice de Edmond e Drapala, segundo Silva e Nakagawa (1995):

$$
T M G=\frac{N_{1} T_{1}+N_{2} T_{2}+\ldots N_{n} T_{n}}{N_{1}+N_{2}+\ldots N_{n}}
$$

em que,

TMG é o tempo médio de germinação das sementes que germinaram no prazo de 60 dias;

$\mathrm{N}_{1}, \mathrm{~N}_{2}, \mathrm{~N}_{\mathrm{n}}$ é o número de sementes germinadas nos tempos $\mathrm{T}_{1}, \mathrm{~T}_{2}$ e $\mathrm{T}_{\mathrm{n}}$, respectivamente.

$\mathrm{O}$ tempo médio de germinação representa a média ponderada do tempo necessário para a germinação, tendo como fator de ponderação a germinação diária. Considerou-se como início de germinação o número de dias requerido para que a primeira semente germinasse.

Os dados obtidos foram submetidos à análise de variância, e as médias, comparadas pelo teste de Tukey, ao nível de $5 \%$ de probabilidade. Os dados de porcentagem de germinação foram previamente transformados em arco-seno $\sqrt{x / 100}$, enquanto os referentes ao início, tempo médio de germinação e número de plântulas obtidas a partir de 50 pirênios foram transformados em $\sqrt{x}$.

\section{RESULTADOS E DISCUSSÃO}

Os pirênios do murucizeiro do clone Açu são de cor parda, rígidos, formato ovalado, pontiagudos na extremidade apical e depressos na porção basal, e apresentam superfície externa reticulada. Essas características são comuns na maioria dos tipos de muruci, conforme Cavalcante (1996). Por outro lado, diferenciam-se da quase totalidade dos tipos ocorrentes em populações naturais e em áreas de cultivo por apresentarem dimensões e peso maiores (Tabela 1).

Em grande parte dos tipos de muruci ocorrentes na Amazônia Brasileira, o peso médio dos pirênios situa-se entre 0,25 g e 0,47 g (Carvalho et al.,1998; Carvalho et al., 2007), enquanto, nos do muruci do clone Açu, o valor observado foi 1,3 a 2,5 vezes superior (Figura 1).

Observaram-se, com maior freqüência, pirênios contendo duas sementes, sendo ínfima a proporção de pirênios desprovidos de sementes (Figura 2), contrastando com Carvalho et al. (1998), que verificaram a presença de, pelo menos, uma semente em cada diásporo e maior freqüência de pirênios com três sementes. No caso de diásporos desprovidos de sementes, constatou-se sempre a existência de, pelo menos, um lóculo no pirênio, indicando que houve fecundação do óvulo, o qual não foi convertido em semente.

As sementes estão localizadas em lóculos seminíferos (Figura 3), cujas paredes internas são de espessura bem menor que as externas. As sementes são pequenas em relação ao tamanho do pirênio e representam apenas $10,12 \%$ do peso deste (Tabelas $1 \mathrm{e} 2$ ). Apresentam tegumento delgado, de cor creme e embrião circinado, que ocupa todo o espaço interno da semente, confirmando as observações de Barroso et al. (1999). Na parede externa de cada lóculo, independentemente de este conter ou não semente, encontra-se um pequeno opérculo oblongo, por onde emerge a plântula.

Constatou-se que o endocarpo, não obstante sua consistência córnea e considerável espessura, é permeável à água, permitindo que as sementes absorvam prontamente essa substância quando semeadas em substrato com disponibilidade hídrica adequada. A absorção de água pelo endocarpo foi rápida, verificando-se a hidratação plena dos tecidos dessa estrutura 24 horas após a semeadura, em processo puramente físico. Por outro lado, a absorção de água pelas sementes foi lenta, observando-se a hidratação máxima dos tecidos somente 120 horas após a semeadura. A curva de absorção de água pelas sementes evidencia as fases 1 e 2 do processo trifásico de absorção de água (Figura 4). Conforme salientam Bewley \& Black (1994), a primeira fase depende do potencial matricial das sementes, e a segunda, cujo início se verificou 96 horas após a semeadura, é dependente do potencial osmótico.

A porcentagem final de germinação foi significativamente maior $(\mathrm{P} \leq 0,05)$ quando os pirênios foram previamente imergidos, durante 24 horas, em solução de ácido giberélico na concentração de $500 \mathrm{mg} . \mathrm{L}^{-1}$, com posterior fratura do endocarpo por compressão. A aplicação desse tratamento pré-germinativo propiciou a obtenção de $93,0 \%$ de germinação, com início e término no oitavo e no quadragésimo-sexto dia após a semeadura, respectivamente. Sementes contidas em pirênios submetidos ao tratamento de água com fratura iniciaram a germinação aos dez dias, tendo o patamar de germinação atingido 52 dias após a semeadura, com 83,5\% de sementes germinadas (Figura 5).

A pré-embebição dos pirênios em solução de ácido giberélico sem posterior fratura do endocarpo melhorou bastante a porcentagem de germinação em relação ao tratamentotestemunha, contudo foi inferior aos tratamentos em que se provocou fratura nos endocarpos, obtendo-se, 50 dias após a semeadura, germinação de $63,5 \%$, valor que persistiu até o final do teste de germinação. Por outro lado, a imersão dos pirênios em água, durante 24 horas, não teve efeito sobre a porcentagem de germinação, nem no tempo requerido para início de germinação 
(Figura 5).

O maior número de plântulas normais por 50 pirênios foi observado nos tratamentos em que os pirênios foram préimergidos em solução de ácido giberélico ou em água e submetidos a fraturas no endocarpo, obtendo-se 87,5 e 74,3 plântulas, respectivamente (Figura 6). Em todos os tratamentos, o número de plântulas normais obtido a partir de 50 pirênios foi maior que o número de plântulas normais computado nos testes de germinação. Nos tratamentos em que se provocaram fraturas no endocarpo ou quando os pirênios foram somente imergidos em solução de ácido giberélico, o número médio de plântulas normais nos pirênios em que ocorreu germinação, situou-se entre 1,7 e 1,9 plântula. Nos demais tratamentos, foi menor, obtendose, em média, 1,3 plântula normal. Isto indica que, quando os pirênios contêm mais de uma semente, estas são viáveis e podem germinar, o que não está de acordo com Cavalcante (1996) que, assinala que quando os pirênios de muruci contêm duas ou mais sementes, somente uma é viável. Quando ocorreu a germinação de mais de uma semente, em um pirênio, o processo ocorreu simultaneamente ou, no máximo, com diferença de dois e três dias, indicando que a resistência do endocarpo e o grau de dormência fisiológica das sementes não variam dentro de um mesmo pirênio.

Fraturas no endocarpo, independentemente de a préembebição ter sido efetuada em água ou em solução de ácido giberélico, aceleraram a germinação das sementes, o que se comprova pela redução no tempo médio de germinação. Quando os pirênios foram pré-embebidos em solução de ácido giberélico, sem posterior fratura no endocarpo, o tempo médio de germinação foi superior ao dos tratamentos anteriores, porém inferior ao dos demais tratamentos (Figura 7).

A demonstração de que fraturas no endocarpo, após pré-embebição dos pirênios em água, condicionam expressivo aumento na porcentagem de germinação e redução no tempo requerido para que as sementes germinem, indica que essa estrutura se constitui na principal barreira para a germinação das sementes de muruci do clone Açu. O endocarpo de murucis do clone Açu, conquanto permeável à água, condiciona dormência exógena, pois, devido sua espessura e consistência córnea, impede o alongamento do embrião, o que contrasta com as observações de Sautu et al. (2007), que atribuem a baixa e lenta germinação de sementes dessa espécie unicamente à dormência fisiológica.

Provavelmente, nesse genótipo de murucizeiro, existam quatro grupos de diásporos no que concerne à dormência: pirênios em que o endocarpo não oferece impedimento à germinação e as sementes não apresentam dormência fisiológica; pirênios em que o endocarpo oferece impedimento ao crescimento do embrião e as sementes não são dormentes; pirênios em que o endocarpo não oferece restrições sérias à germinação, mas as sementes são fisiologicamente dormentes, e pirênios em que o endocarpo é bastante resistente, impedindo o crescimento do embrião e as sementes são fisiologicamente dormentes.

As sementes do primeiro grupo de pirênios germinam prontamente, não requerendo a aplicação de tratamentos pré- germinativos, embora tenham sua germinação acelerada quando os pirênios são previamente imergidos em solução de ácido giberélico (Figura 5), haja vista que essa substância, além de promover a germinação de sementes dormentes, acelera a germinação de sementes não-dormentes (Zaidan \& Barbedo, 2004). A proporção de pirênios desse grupo foi em torno de $10 \%$, ou seja, representada pelas sementes que germinaram no prazo de 30 dias sem aplicação de tratamentos pré-germinativos, conforme critério adotado por Sautu et al. (2007).

Os pirênios do segundo grupo são os que ocorrem em maior proporção, haja vista o substancial aumento na porcentagem de germinação e a significativa redução no tempo médio de germinação quando se efetuou fratura no endocarpo após a pré-embebição em água (Figuras 5 e 7). A identificação de diásporos de muruci com essa característica é conflitante com as observações de Sautu et al. (2007), que atribuem a baixa e lenta germinação de sementes dessa espécie unicamente à dormência fisiológica.

A ocorrência de pirênios em que a germinação das sementes é bloqueada somente por mecanismo de dormência fisiológica, é suportada pelo fato de que se observou considerável aumento na porcentagem de germinação quando os diásporos foram imergidos em solução de ácido giberélico sem que se tenha provocado fratura no endocarpo. Por outro lado, a presença de pirênios em que ocorre tanto dormência exógena, imposta pelo endocarpo, como dormência endógena, é evidenciada pelo aumento na porcentagem de germinação das sementes contidas em pirênios que foram imergidos em solução de ácido giberélico e submetidos à fratura em relação ao tratamento em que os pirênios foram imergidos em água e posteriormente fraturados (Figura 5).

Em outros tipos de muruci, é provável a ocorrência de pirênios com as características anteriormente descritas. No entanto, há de se admitir que ocorram pronunciadas variações na proporção dos quatro grupos de pirênios. Tal assertiva é baseada no fato de que existem grandes diferenças na porcentagem e na velocidade de germinação entre sementes de diferentes clones. Por exemplo, sementes do clone Cristo, contidas em pirênios não-submetidos a tratamentos prégerminativos, apresentaram porcentagem de germinação superior a 80\%, 60 dias após a semeadura (Carvalho et al., 2007), provavelmente por apresentarem elevada proporção de pirênios em que o endocarpo não condiciona dormência exógena e as sementes não apresentam dormência físiológica.

A hipótese de dormências exógena e endógena regulando a germinação de sementes de muruci foi primeiramente levantada com base no fato de que sementes contidas em pirênios nãosubmetidos a tratamentos pré-germinativos, embora não germinando, mantinham-se viáveis no substrato de germinação, por períodos superiores a 200 dias. Assim sendo, e considerando o fato de que o endocarpo é permeável à água, seria inconsistente para uma espécie de semente com comportamento ortodoxo manter-se viável por tão longo tempo, com elevado teor de água. Inferiu-se, então, que as estratégias que garantem a manutenção da viabilidade de sementes do muruci, estão associadas à existência de dormência fisiológica, a qual permite que o embrião apresente metabolismo ativo durante a embebição, sem que haja, 
concomitantemente, diferenciação e crescimento, até o momento em que o pequeno opérculo presente no endocarpo perca sua resistência, possibilitando então a emergência da plântula (Carvalho et al., 1998; Carvalho et al., 2007).

TABELA 1 - Caracterísitcas biométricas de pirênios de murucizeiro (Byrsonima crassifolia (L.) Rich), clone Açu. BelémPA, 2007.

\begin{tabular}{lccc}
\hline \multirow{2}{*}{ Característica } & \multicolumn{3}{c}{ Valor } \\
\cline { 2 - 4 } & Mínimo & Médio & Máximo \\
\hline Peso $(\mathrm{g})^{2}$ & 0,36 & $0,62( \pm 0,09)$ & 0,85 \\
Comprimento $(\mathrm{cm})$ & 0,94 & $1,10( \pm 0,07)$ & 1,29 \\
Diâmetro $(\mathrm{cm})$ & 0,48 & $1,02( \pm 0,09)$ & 1,16 \\
Se mentes por endocarpo (número) & 0,00 & $2,07( \pm 0,64)$ & 3,00 \\
Espessura da parede externa do endocarpo $(\mathrm{mm})$ & 1,21 & $2,24( \pm 0,30)$ & 2,96 \\
Espessura da parede interna do endocarpo $(\mathrm{mm})$ & 0,27 & $0,49( \pm 0,09)$ & 0,70 \\
Relação entre o peso das sementes e do pirênio $(\%)$ & 0,00 & $10,12 \quad( \pm 2,87)$ & 16,71 \\
\hline
\end{tabular}

1. Valores representam médias ( \pm desvio-padrão), $\mathrm{n}=100$ pirênios.

2. Teor de água igual a 5,0\%.

TABELA 2 - Caracterísitcas biométricas de sementes de muruci (Byrsonima crassifolia L. (Rich), clone Açu. BelémPA, 2007.

\begin{tabular}{lccc}
\hline Característica & Mínimo & Médio $^{1}$ & Máximo \\
\hline Peso da semente $(\mathrm{g})^{2}$ & 0,0034 & $0,0310( \pm 0,0034)$ & 0,0377 \\
Comprimento $(\mathrm{mm})$ & 4,1 & $5,2( \pm 0,4)$ & 6,3 \\
Largura $(\mathrm{mm})$ & 2,1 & $4,1( \pm 0,4)$ & 4,8 \\
Espessura $(\mathrm{mm})$ & 1,7 & $2,6( \pm 0,2)$ & 3,1 \\
\hline
\end{tabular}

1. Valores representam médias ( \pm desvio-padrão), $\mathrm{n}=100$ pirênios.

2. Teor de água igual a $4,9 \%$.

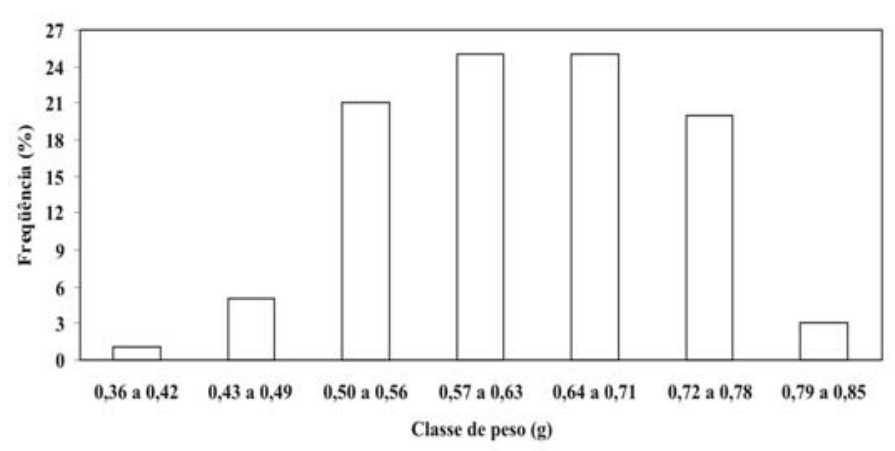

FIGURA 1 - Freqüência de peso de pirênios de muruci (Byrsonima crassifolia (L.) Rich.), clone Açu. Belém-PA, 2007.

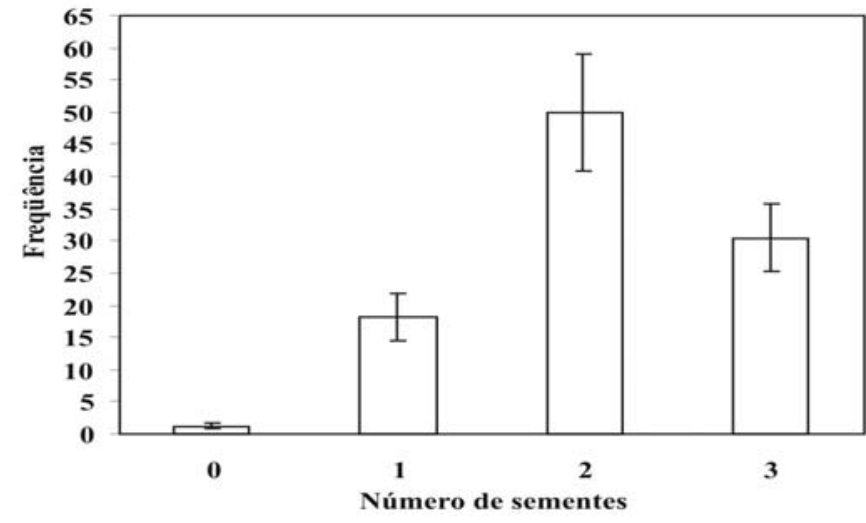

FIGURA 2 - Freqüência de pirênios de muruci (Byrsonima crassifolia (L.) Rich.) do clone Açu. desprovidos de sementes e com uma, duas e três sementes. Belém-PA, 2007. (As barras representam o desviopadrão).

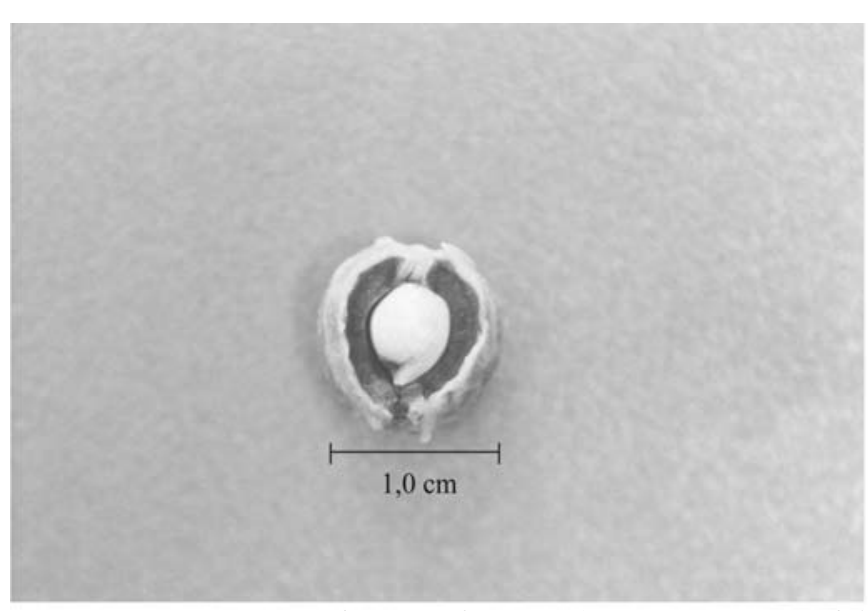

FIGURA 3 - Semente de muruci “Açu“" (Byrsonima crassifolia (L.) Rich.) no interior do pirênio. Belém-PA, 2007.

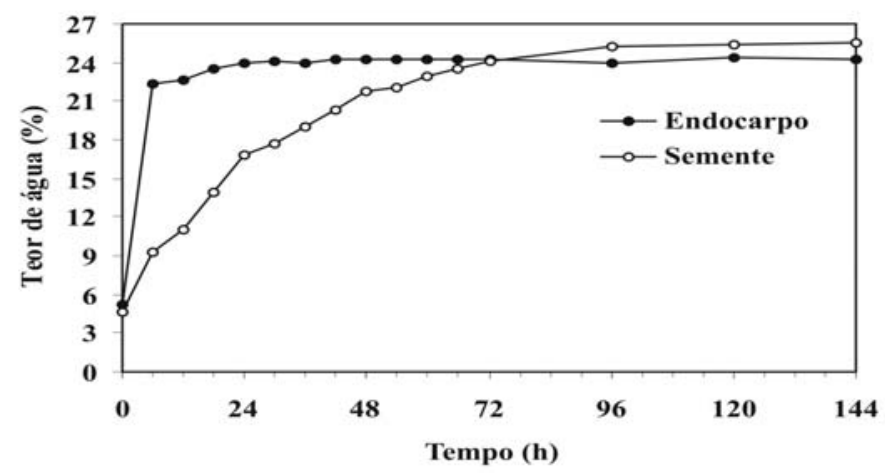

FIGURA 4 - Teor de água no endocarpo e nas sementes de muruci (Byrsonima crassifolia (L.) Rich.) do clone Açu após diferentes períodos de semeadura dos pirênios. Belém-PA, 2007. 


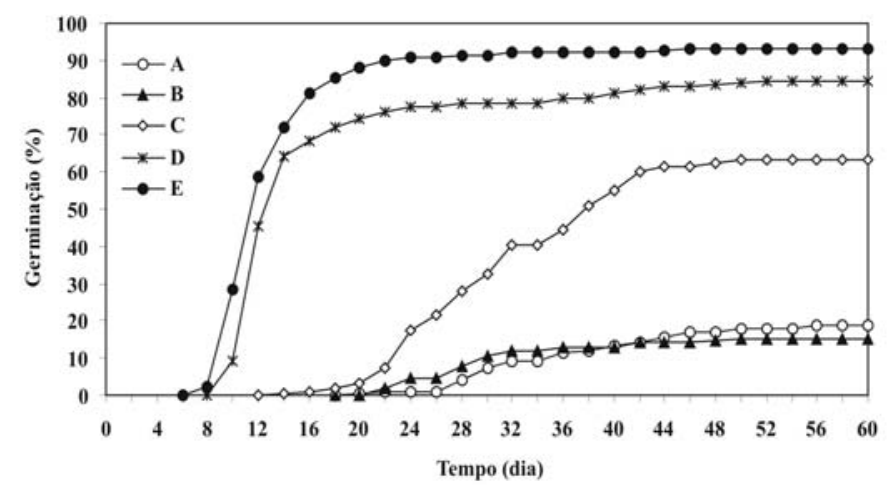

FIGURA 5 - Germinação de sementes de muruci (Byrsonima crassifolia (L.) Rich.) do clone Açu, em função do tempo e de tratamentos para superação da dormência (A - testemunha; B - pré-embebição em água; $\mathrm{C}$ - Pré-embebição em ácido giberélico; D - Pré-embebição em água e fratura no endocarpo; E - Pré-embebição em ácido giberélico e fratura do endocarpo). Belém-PA, 2007.

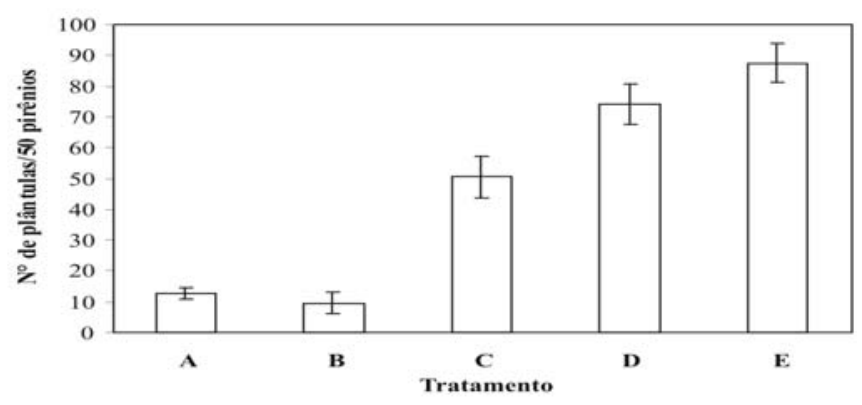

FIGURA 6-Número de plântulas obtidas a partir de 50 pirênios de muruci (Byrsonima crassifolia (L.) Rich.) do clone Açu, em função de tratamentos prégerminativos (A - testemunha; $\mathrm{B}$ - pré-embebição em água; $\mathrm{C}$ - Pré-embebição em ácido giberélico; D - Pré-embebição em água e fratura no endocarpo; E-Pré-embebição em ácido giberélico e fratura do endocarpo). Belém-PA, 2007.

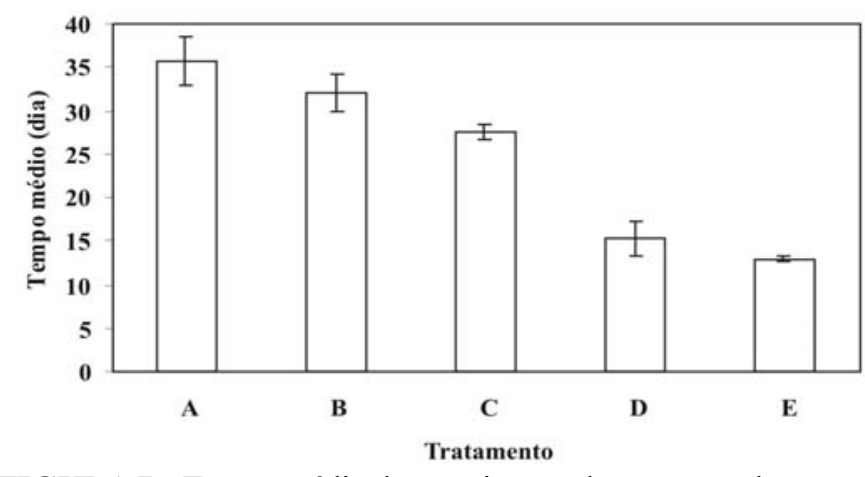

FIGURA 7 - Tempo médio de germinação de sementes de muruci (Byrsonima crassifolia (L.) Rich.) do clone Açu submetidas a tratamentos para superação da dormência (A - testemunha; B - pré-embebição em água; $\mathrm{C}$ - Pré-embebição em ácido giberélico; D - Pré-embebição em água e fratura no endocarpo; E - Pré-embebição em ácido giberélico e fratura do endocarpo). Belém-PA, 2007.

\section{CONCLUSÕES}

1-Os pirênios do muruci do clone Açu apresentam dimensões e peso superiores ao da maioria dos pirênios de outros tipos de muruci e geralmente apresentam duas sementes.

2-O endocarpo constitui-se no principal obstáculo para a germinação de sementes de muruci do clone Açu, embora algumas sementes apresentem também dormência fisiológica.

3-Fraturas provocadas no endocarpo, após prévia imersão dos pirênios em solução de ácido giberélico ou em água, constituem-se em métodos eficientes e eficazes para promover a germinação de sementes de muruci do clone Açu.

\section{AGRADECIMENTOS}

Os autores agradecem ao Conselho Nacional de Desenvolvimento Científico e Tecnológico (CNPq) pelo apoio (processo $\mathrm{N}^{\circ} 480760 / 2007-1$ ).

\section{REFERÊNCIAS}

BARROSO, G.M.; MORIM, M.P.; PEIXOTO, A.L. ICHASO, C.L.F. Frutos e sementes: morfologia aplicada à sistemática de dicotiledôneas. Viçosa: UFV, 1999. 443p.

BEWLEY, J.D.; BLACK, M. Seeds: physiology of development and germination. 2ed. New York: Plenum Press, 1994. 445p.

BRASIL. Ministério da Agricultura e Reforma Agrária. Regras para análise de sementes. Brasília:SNDA/DNDV/CLAV, 1992. 365 p.

CALZAVARA, B.B.G. Fruteiras: abacaxizeiro, cajueiro, goiabeira, maracujazeiro, murucizeiro. Belém: IPEAN, 1970. 42p. (IPEAN. Série Culturas da Amazônia, 1)

CARVALHO, J.E.U. de; MÜLLER, C.H. Biometria e rendimento percentual de polpa de frutas nativas da Amazônia. Belém: Embrapa Amazônia Oriental, 2005. 4p. (Embrapa Amazônia Oriental. Comunicado Técnico, 139).

CARVALHO, J.E.U. de; MÜLLER, C.H.; NASCIMENTO, W.M.O. do Características físicas e de germinação de sementes de espécies frutíferas nativas da Amazônia. Belém: EmbrapaCPATU, 1998. 18p. (Embrapa-CPATU. Boletim de Pesquisa, 203).

CARVALHO, J.E.U. de; NASCIMENTO, W.M.O. do; MÜLLER, C.H. Propagação do Murucizeiro (Byrsonima crassifolia (L.) Rich.). In: CARVALHO, J.E.U. de; NASCIMENTO, W.M.O. do; MÜLLER, C.H. Produção de mudas de espécies frutíferas nativas da Amazônia. Fortaleza: Instituto Frutal, 2007. p. 87-99.

CAVALCANTE, P.B. Frutas comestíveis da Amazônia. Belém: CNPq/ Museu Paraense Emílio Goeldi, 6 ed. 1996, 279p. (Coleção Adolpho Ducke). 
EDWARDS, T.I. Relations of germinating soybeans to temperature and length of incubation time. Plant Physiology, Rockville, v.9, p.1-30, 1934.

MORTON, J.F. Fruits of warm climates. Miami: University of Miami, 1987.507p.

ROOSMALEN, M.G.M. van. Fruits of the Guianan Flora. Utrecht: Institute of Systematic Botany and Silvicultural Department of Wageningen Agricultural University, 1985. 483p.

SAUTU, A.; BASKIN, J.M., BASKIN, C.C.; CONDIT, R. Studies on the biology of 100 native species of trees in a seasonal moist tropical forest, Panama, Central America. Maryland, Forest Ecology Management, Amsterdan, v.234, p.245-263. 2006.

SAUTU, A.; BASKIN, J.N., BASKIN, C.C.; DEAGO, J.; CONDIT, R. Classification and ecological relationships of seed dormancy in a seasonal moist tropical forest, Panama, Central America. Seed Science Research, Cambridge, v.17, p.127-140. 2007.
SILVA, J.B.C.; NAKAGAWA, J. Estudo de fórmulas para o cálculo da velocidade de germinação. Informativo ABRATES, Londrina, v.5, n.1, p.62-73, 1995.

SOUZA, F.M.; SOARES JÚNIOR, F.J.; TEIXEIRA, A. de P. Diversidade e similaridade florística em cinco fragmentos de cerrado no município de Itirapina, SP. Disponível em www.ib.unicamp.br/profs/fsantos/relatorios/he211b.polf. Acesso em: 11 ago. 2006.

ZAIDAN, L.B.P.; BARBEDO, C.J. Quebra de dormência em sementes. In: FERREIRA, A.G.; BORGHETTI, A.G. (orgs.) Germinação: do básico ao aplicado. Porto Alegre: Artmed, 2004, p. 149-162. 